\title{
Maternal Obesity and the First Birth: A Case for Targeted Contemporary Maternity Care
}

\author{
Valerie J. Slavin, Jennifer Fenwick, and Jenny Gamble
}

BACKGROUND: Obesity in childbearing women is associated with poorer pregnancy and birth outcomes, particularly caesarean section, compared with normal-weight women. The high caesarean section rate may reflect care and outcomes which occur at the time surrounding the first birth.

AIM: To describe the birth outcomes of extremely obese pregnant women (body mass index [BMI] of 40 or more) experiencing their first birth.

METHODS: Clinical audit was used to systematically review the care and birth outcomes of all extremely obese pregnant women experiencing their birth at one study site during a 2-year period in 2009 and 2010. Fifty participants birthed during the study period. Data were collected from booking to discharge from the maternity service and included variables such as model of care, number of appointments, and obstetric and neonatal outcomes. Descriptive statistics were used to describe and synthesize the data. Inferential statistics were used to draw inferences about the population.

RESULTS: Obese women rarely had contact with a midwife, except at booking, receiving a standard model of care provided by numerous caregivers, most often inexperienced medical staff. More than half of the obese women experienced a caesarean section (56\%), 2.3 times that of normal-weight primiparous women who birthed at the study site during the same period (24.2\%). This was despite $64 \%$ experiencing normal pregnancy free from any complication. For women who planned to labor, birth intervention including induction of labor, augmentation for slow labor, epidural, and continuous cardiotocography was high. Caesarean occurred most often for "failure to progress" and "failed induction."

CONCLUSION: Clinical audit was useful in determining information, which suggests current maternity care provision is not meeting the needs of extremely obese women experiencing their first birth.

IMPLICATIONS FOR PRACTICE: The development of effective, targeted antenatal care designed to meet the needs of extremely obese women is recommended as are strategies to keep birth normal.

KEYWORDS: pregnancy; body mass index; morbid obesity; caesarean section; gestational diabetes; cardiovascular pregnancy complications

\section{INTRODUCTION}

The prevalence of maternal obesity is increasing exponentially with reports of it reaching epidemic proportions throughout the developed world, mirroring that of obesity in the general population (World Health Organization [WHO], 2012). This is concerning given that maternal obesity is now recognized as a key risk factor for adverse outcomes for both women and their babies
(Centre for Maternal and Child Enquiries [CMACE], 2011) such as hypertensive disorders (Abenhaim, Kinch, Morin, Benjamin, \& Usher, 2007; Dodd, Grivell, Nguyen, Chan, \& Robinson, 2011; Knight, Kurinczuk, Spark, \& Brocklehurst, 2010; Mbah et al., 2010), diabetes (Abenhaim et al., 2007; Athukorala, Rumbold, Willson, \& Crowther, 2010; Dodd et al., 2011; Knight et al., 2010), thromboembolism (CMACE, 2011), and caesarean section (CS). The number of women experiencing 
CS has been shown to increase in a dose-related fashion with increasing body mass index (BMI; Abenhaim et al., 2007; Bhattacharya, Campbell, Liston, \& Bhattacharya, 2007; Chu et al., 2007; Khashan \& Kenny, 2009; Knight et al., 2010; Mantakas \& Farrell, 2010; Mbah et al., 2010; Poobalan, Aucott, Gurung, Smith, \& Bhattacharya, 2009; Sebire et al., 2001; Usha Kiran, Hemmadi, Bethel, \& Evans, 2005). Work undertaken with Australian childbearing women has demonstrated comparable trends (Athukorala et al., 2010; Dodd et al., 2011). Similarly, health statistics data obtained for one hospital in South East Queensland revealed that in 2010, the CS rate for normal-weight women (BMI of 19-24) was $24.5 \%$, increasing exponentially with BMI to $29.1 \%$ for BMI of $25-29,32.9 \%$ for BMI of $30-34,33.3 \%$ for BMI of 35-39, and $43.8 \%$ for BMI of 40 or more (Health Statistics Centre Queensland Health, 2012).

In addition, there is a growing body of evidence that identifies a strong association between primiparity and increased CS rates in obese women. A systematic review of 11 studies $(N=209,193)$ conducted by Poobalan et al. (2009) reported obese primiparous women (defined as BMI of 35 or more) were three times more likely to experience CS compared with their normal-weight counterparts (crude pooled odds ratio 3.38, 95\% CI [2.49, 4.57]). Similar results are reported by others (Bhattacharya et al., 2007). Although there is no doubt that maternal ill health and subsequent concerns for the fetus are likely to play some part in the increased rates of CS, the sheer number of caesareans in this group of women suggests that there may be other contributing factors.

One of the most important strategies for reducing the overall CS rate is to reduce the number of primary CSs. Gaining a better understanding of all the factors associated with a primary caesarean in this group of women may assist health care professionals improve the quality of maternity care and ultimately, a woman's reproductive health.

Although there is a lack of evidence pertaining to the care and outcomes of women with very severe obesity (defined as BMI of 40 more; WHO, 2000), there is also no agreed term to describe obesity subgroups beyond this BMI. Recent work describing the prevalence and outcomes of women with a BMI of 50 or greater have used various terms including super obese, morbid obese, or extremely obese (Australasian Maternity Outcomes Surveillance System, 2010; Knight et al., 2010; Mbah et al., 2010). Because there is currently no standard agreed terms, this article will define subgroups not currently described elsewhere as moderately obese (BMI of 40-44), extremely obese (BMI of 45-49), and super-extremely obese (BMI of 50 or more).
AIM

This article presents the birth outcomes of moderate to super-extremely obese pregnant women (BMI of 40 or more) experiencing their first birth. The results are part of a larger study exploring the health service usage and outcomes of extremely obese Australian women (Slavin, Fenwick, \& Gamble, 2013).

\section{Ethical Approval}

Ethical approval to conduct the project was granted by the Hospital District Human Research Ethics Committee (HREC) and Griffith University HREC.

\section{METHOD}

This study used a retrospective, clinical observation research design.

\section{Setting}

The study was carried out at one maternity unit in South East Queensland, Australia. The unit manages low-, medium-, and selected high-risk pregnancies for approximately 3,500 women per year. Midwife-led antenatal care is offered to women with no medical or obstetric complications. Specialist care is provided to women who have identified risk factors and/or who develop complications during pregnancy including women with moderate to extreme obesity. Between 2009 and 2010, 6,995 women birthed at the study site. This included 3,082 (44.1\%) women experiencing their first birth, which is only slightly higher than the national average of $41.6 \%$ ( $\mathrm{Li}, \mathrm{McNally}$, Hilder, \& Sullivan, 2011). A further 3,913 (55.9\%) women experienced their second or subsequent births. The overall prevalence of moderate to super-extremely obese women (BMI of 40) was 21.9 per 1,000, $(n=153$; Health Statistics Centre Queensland Health, 2010).

\section{Sample}

The primary target population was 50 pregnant women experiencing their first birth with a self-reported prepregnancy booking BMI of 40 who birthed at the study site between January 1, 2009 and December 31, 2010. This represents $32.7 \%$ of the larger group. 


\section{Data Collection}

Using a specifically designed audit tool, clinical audit was used to identify several outcome variables including maternity service use and birth outcomes from booking to discharge from maternity care (Slavin, Fenwick, \& Gamble, 2013).

\section{Data Analysis}

Data were entered into Statistical Package for the Social Sciences (SPSS) database version 19. Descriptive statistics were initially used to describe and synthesize the data. Inferential statistics were subsequently used to make inferences about the population. Relationships between categorical variables were examined using chisquare analyses, between continuous variables using Pearson's product-moment correlation test and for relationship between continuous and categorical variables using one-way analysis of variance (ANOVA). An alpha level of 0.05 was used for all statistical tests. Outcome measures were defined according to the definitions within the literature.

\section{RESULTS}

\section{Participant Characteristics}

Fifty moderate to super-extremely obese women birthed their first baby during the study period. The average age of participants was 28 years $(S D=5)$, which is the same as the Australian national average for 2009 ( $\mathrm{Li}$ et al., 2011). Most women were in the moderate obese group (BMI of $40-44 ; n=37,74 \%$ ), with the remaining $26 \%$ of women being in the extreme to super-extreme obese groups.

\section{Antenatal: Model of Care}

Women generally booked for maternity care at 20 weeks' gestation (range $=8-38$ weeks) and attended 12 (range $=1-21$ ) antenatal visits. Most women experienced shared care with their general practitioner attending the hospital at some point during their pregnancy. When women did attend the hospital antenatal clinic, they were seen by several different clinicians ( $n=6,1-16$; see Table 1), most of whom were medical staff in various stages of their training program (residents and registrars). Most women only saw a midwife
TABLE 1 Overview: Antenatal Visits Experienced by Obese Women

\begin{tabular}{|c|c|c|c|}
\hline $\begin{array}{l}\text { ANTENATAL (AN) } \\
\text { APPOINTMENTS }\end{array}$ & $N=\mathbf{5 0}$ & $\%$ & $\begin{array}{c}M d n \\
\text { (RANGE) }\end{array}$ \\
\hline Booking gestation (weeks) & & & $20(8-38)$ \\
\hline Number of AN visits & & & $12(1-21)$ \\
\hline Number of staff seen & & & $6(1-16)$ \\
\hline Number of GP visits & 43 & 86 & $5(0-15)$ \\
\hline Number of midwife visits & 49 & 98 & $1(0-7)$ \\
\hline Number of junior doctor visits ${ }^{a}$ & 43 & 86 & $2(0-7)$ \\
\hline Number of senior doctor visits ${ }^{b}$ & 37 & 74 & $1(0-8)$ \\
\hline $\begin{array}{l}\text { Number of obstetric consultant } \\
\text { visits }\end{array}$ & 7 & 14 & $0(0-2)$ \\
\hline $\begin{array}{l}\text { Number of failure to attend } \\
\text { visits }^{c}\end{array}$ & 26 & 54 & $1(0-5)$ \\
\hline AN education classes & 24 & 48 & \\
\hline
\end{tabular}

Note. GP = general practitioner.

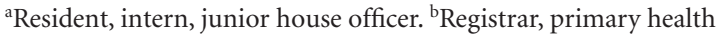
organization. ${ }^{\mathrm{c}}$ Excludes two stillbirths.

at their booking visit. In this group of first-time mothers, the nonattendance rate was $55.3 \%$, five times the nonattendance rate of the general maternity population during the same period (10.8\%; Decision Support Services Queensland Health, 2012). Just less than half the women attended some form of antenatal education classes $(n=24,48 \%)$.

Although 32 women (64\%) experienced normal, healthy pregnancies free from complications, $8(16 \%)$ women developed or were treated for hypertension and $10(20 \%)$ for diabetes. The development or treatment of both diabetes and hypertension was rare $(n=2,4 \%)$.

\section{Birth Outcomes}

\section{Labor}

Only 17 (34\%) women experienced spontaneous onset of labor, whereas $25(50 \%)$ experienced an induction of labor (IOL). The most common reason for IOL was postdates pregnancy $(n=8,32 \%)$. Hospital policy at the time of data collection was routine IOL at term plus 10 days regardless of cervical favorability. The other main reasons for induction were diabetes $(n=6,24 \%)$, prelabor rupture of membranes $(n=5,20 \%)$, and hypertensive disease $(n=3,12 \%)$. One woman was induced following an intrauterine fetal death at 27 weeks' gestation. Eight separate reasons were provided for IOL.

Four women who commenced the induction procedure with the administration of vaginal synthetic prostaglandin did not dilate sufficiently to allow artificial rupture of membranes (ARM). A further two 
women did experience ARM and synthetic oxytocin infusion but did not establish in labor. All four women subsequently experienced a CS for "failed IOL."

For women who experienced labor $(n=38)$, birth interventions were high. In addition to the high IOL rate, a further 13 (34.2\%) women experienced augmentation with either ARM and/or synthetic oxytocin infusion following a diagnosis of dysfunctional labor.

Although 19 women (50\%) had an epidural sited during labor, which subsequently lead to electronic fetal monitoring using continuous cardiotocography (CTG), almost all the women (95\%) with a live fetus were monitored in this way. Most babies were monitored directly using a fetal scalp electrode $(n=25,65.8 \%)$. Perhaps not surprisingly, less than $40 \%$ of the women were reported to be mobile in labor (15 out of 38, 39.5\%).

\section{Birth Mode}

Twenty-two women birthed vaginally (spontaneously [ $n=15,30 \%]$, assisted $[n=7,14 \%]$; see Table 2$)$. In total, 28 women (56\%) birthed their baby by CS. This is almost 2.5 times that of normal-weight primiparous women at the study site during the same period. Of the 1,386 normal-weight (defined as BMI of 20-24) primiparous women, 335 (24.2\%) experienced CS.

Seven women experienced planned elective CS, and a further 21 experienced emergency CS (see Table 3). One woman in the emergency group was booked for elective surgery for breech but experienced emergency CS following the onset of spontaneous labor.

TABLE 2 Overview: Labor Onset and Mode of Birth for Women Experiencing Their First Birth

$\begin{array}{lrrr} & \text { N }=\mathbf{5 0} & \text { \% } & \text { M (SD) } \\ \text { Age (years) } & & & 28.4(5.3) \\ \text { Onset of labor } & & & \\ \quad \text { Spontaneous } & 17 & 34 & \\ \quad \text { Induction of labor } & 25 & 50 & \\ \quad \text { Elective caesarean } & 8 & 16 \\ \text { Mode of birth } & & \\ \quad \text { Spontaneous vaginal } & 15 & 30 \\ \quad \text { birth } & & & \\ \quad \text { Vaginal (vacuum) } & 4 & 8 \\ \quad \text { Vaginal (forceps) } & 3 & 6 \\ \quad \text { Caesarean section } & 28 & 56 \\ \text { BMI group } & & \\ 40-44 & 37 & 74 \\ 45-49 & 6 & 12 \\ \geq 50 & 7 & 14\end{array}$

Note. $\mathrm{BMI}=$ body mass index.
TABLE 3 Indication for Caesarean Section

(Elective and Emergency; $N=28$ )

\begin{tabular}{lcc} 
& $\begin{array}{c}\text { ELECTIVE } \\
(\boldsymbol{N}=7)\end{array}$ & $\begin{array}{c}\text { EMERGENCY } \\
(\boldsymbol{N}=\mathbf{2 1}) \\
\boldsymbol{n}(\%)\end{array}$ \\
$\begin{array}{l}\boldsymbol{n}(\%) \\
\text { Failure to progress }\end{array}$ & $10(35.7)$ \\
$\begin{array}{l}\text { Failed IOL } \\
\text { Fetal distress }\end{array}$ & $6(21.4)$ \\
Breech & & $4(14.3)$ \\
Maternal request & $2(7.1)$ & $1^{\mathrm{a}}(3.6)$ \\
Vasa praevia & $2(7.1)$ & \\
Macrosomia & $1(3.6)$ & \\
High head & $1(3.6)$ & \\
\hline
\end{tabular}

Note. $\mathrm{IOL}=$ induction of labor.

aplanned elective CS for breech; progressed to emergency CS following spontaneous labor.

For the 20 unplanned CS, there were eight different reasons documented. However, "failure to progress" and "failed induction" were the most common and accounted for more than half of the caesareans performed. Breech presentation and "maternal request" accounted for more than half of all elective procedures (see Table 3). No woman was documented as having a planned elective CS for the comorbidities associated with obesity.

When comparing women who birthed vaginally to women who birthed by CS following planned labor (excluding planned elective CS), the groups of women were similar in many respects. There was no significant difference in maternal age, infant birth weight, onset of labor, epidural, diabetes, or hypertension for women who birthed vaginally or by CS. Furthermore, there was no significant association between BMI group and mode of birth $\chi^{2}(2,[n=42]=.81, p=.67$, Cramér's $\mathrm{V}=.14)$.

\section{Neonatal Outcomes}

There were 50 babies born including 2 stillborn babies born at 22 and 27 weeks' gestation. This is a concerning finding because the stillbirth rate of 40 per 1,000 births is more than five times that of the general Australian population ( $4 \%$ vs. $0.78 \%$, retrospectively; Li et al., 2011). Live babies were generally born in good condition, with 5 out of 48 (10.4\%) babies requiring neonatal resuscitation. Although 4 out of $48(8.3 \%)$ required intermittent positive pressure ventilation via bag and mask, this is only slightly higher than the general population of 7.2\% (Li et al., 2011). One baby (2.1\%) required cardiac compressions, which is six times higher than the general population of $0.3 \%$ (Li et al., 2011). 
Twenty-seven (56.3\%) babies were admitted to or were cared for by the special care nursery. Main reasons were maternal diabetes $(n=7)$, suspected infection $(n=6)$, and macrosomia (birth weight more than $4,500 \mathrm{~g} ; n=5$ ). Two live-born babies were premature at 35 and 36 weeks' gestation. Average birth weight was $3,720 \mathrm{~g}(S D=519 \mathrm{~g}){ }^{1}$

\section{DISCUSSION}

The results reported in this article demonstrate that moderate to super-extremely obese women having their first baby commonly experience quite different birth outcomes to those of normal-weight women and the general population. Although the overall CS rate for primiparous women in Australia is $32.8 \%$ (Li et al., 2011) and for the study site for the same period was $26.6 \%$, the CS rate for the cohort of women in this study was more than double (56\%). This was despite $64 \%$ of the women experiencing normal, healthy pregnancies free from complications other than obesity itself.

For women who planned to labor, birth interventions were high. For example, almost $60 \%$ of these women experienced an induction. Although the authors of two systematic reviews (Caughey et al., 2009; Gülmezoglu, Crowther, \& Middleton, 2006) concluded that IOL does not increase the CS rate, a significant methodological critique of this work calls into question the appropriateness of routine IOL for well women and fetuses before 42 weeks' gestation (King, Pilliod, \& Little, 2010; Mozurkewich, Chilimigras, Koepke, Keeton, \& King, 2009). There is also increasing evidence that primiparous women having an IOL are the largest group contributing to the CS rate (Brennan, Murphy, Robson, \& O'Herlihy, 2011; Slavin \& Fenwick, 2012). Certainly, one could argue that the risk of stillbirth in extremely obese pregnant women perhaps justifies IOL. Clinicians, however, need to assist women carefully weigh up the risks because surgical birth itself is associated with increased morbidity especially in this group of women (Belizán, Althabe, \& Cafferata, 2007; Stivanello et al., 2010).

Similarly, rates of augmentation for dysfunctional labor were also high in this study with more than $90 \%$ of women experiencing either IOL or augmentation. With a strong association between the use of Syntocinon and increased perceptions of pain, it is not surprising that half the women used epidural for pain management (Hildingsson, Karlström, \& Nystedt, 2011). Likewise, the use of continuous fetal monitoring (CTG) was high with all but two women being monitored in this way.
Although there are often concerns with being able to accurately listen and record fetal heart rates in extremely obese women, the use of CTG is strongly associated with increased rates of CS (Alfirevic, Devane, \& Gyte, 2006).

In light of the increasing CS rate, there is currently an international drive to "keep birth normal" particularly during the first birth (Commonwealth of Australia, 2011; NSW Department of Health, 2010; Maternity Care Working Party, Royal College of Midwives, Royal College of Obstetricians and Gynaecologists, National Childbirth Trust, 2007). The results of this study add to the existing literature and support the need to keep birth normal and avoid unnecessary interventions especially in obese women having their first baby. In this group of childbearing women, although some might argue that birth interventions should be considered "part and parcel" of care, the dilemma of whether such intervention acts as a paradox or panacea appears clear. Obese women experienced very high rates of birth intervention including IOL, augmentation, epidural, and CTG use. Although there is now increasing evidence to suggest IOL should be reserved only for those women with clear medical indications, the obese women in this study experienced IOL for a myriad of ambiguous reasons. Given the evidence, one could postulate that the high rate of medical intervention that occurred during labor may in fact be a mediating factor contributing to the high CS rate experienced by primiparous obese women who plan to labor. Consequently, there is a need to identify strategies aimed at reducing unnecessary interventions in labor especially for those women experiencing their first labor and birth.

\section{Antenatal Care-A Gift or Pandora's Box?}

Although each woman's pregnancy, labor, and birth process contribute to her birth outcomes, there is now a substantial body of evidence that suggests that how women are cared for during their pregnancy and labor can significantly affect their birth outcomes. For example, continuity of midwifery care is associated with reduced birth interventions (Hodnett, Gates, Hofmeyr, Sakala, \& Weston, 2011; Jackson et al., 2003) as well as increased vaginal birth rates, reduced CS rates, and reduced special care nursery admissions (Hartz, Foureur, \& Tracy, 2012; Hatem, Sandall, Devane, Soltani, \& Gates, 2008; Henderson, Hornbuckle, \& Doherty, 2007; Sandall, Soltani, Gates, Shennan, \& Devane, 2013; Turnbull et al., 2009). The women in this study predominantly experienced fragmented medical care. When accessing 
hospital care, these women were mainly seen by medical practitioners still in various stages of their training program with limited midwifery as well as consultant input. The care received by the women included in this study mirrors that of the general maternity population within the study site. Most women who currently attend hospital for pregnancy care receive limited continuity of care in busy clinics. Medical clinics are routinely overbooked with no midwifery support. Women who develop complex needs therefore often receive no midwifery care. The findings of this study may therefore be seen in other high-risk groups of women who receive routine hospital-based obstetric care.

The number of women not attending appointments was also significant. For example, more than half the women ( $n=26,55 \%)$ had missed appointments with 13 women missing two or more appointments. This is five times the rate in the general pregnant population (10.8\%; Decision Support Services Queensland Health, 2012). There may have been a myriad of reasons for this outcome such as lack of transport and poor social circumstances. Given the high numbers, one could also postulate that perhaps nonattendance reflected dissatisfaction with service provision. Certainly, those challenging standard systems of medicalized maternity care would suggest this model of antenatal care to be somewhat dysfunctional with multiple care providers; time constraints; limited resources; and unclear aims, values, and philosophies influencing the care provided (Dahlen, Barclay, \& Homer, 2010b; Homer, Brodie, \& Leap, 2008; Page, 2008). Australian researchers Hartz et al. (2012) described standard care as "predominantly fragmented, organisation and/or practitioner-centric" (p. 40). The women in this study received medicalized, fragmented antenatal care. Midwifery care was all but nonexistent except for the booking visit. Within this context, it is likely that little attention was paid to their individual needs and preferences, quality preparation for birth, or women's knowledge or understanding of the maternity care system.

\section{Implication for Practice}

To meet the needs of obese women experiencing their first pregnancy and birth, targeted maternity care may be the answer. Targeted maternity care has been shown to be an effective strategy in meeting the needs of several vulnerable groups of women (Grady \& Bloom, 2004; Ickovics et al., 2003). Our work suggests that primiparous women with a BMI of 40 or more should be viewed as a vulnerable group for several reasons. First, maternal obesity is associated with a higher incidence of depression particularly in adolescent females (Pickering, Grant, Chou, \& Compton, 2007; Blaine, Rodman, \& Newman, 2007), cigarette smoking, (Cupul-Uicab et al., 2012), domestic violence (Huang, Yang, \& Omaye, 2011), asthma (Benninger \& McCallister, 2010), and obstructive sleep apnea (Ursavas, Karadag, Nalci, Ercan, \& Gozu, 2008), all of which can have serious negative sequelae for the growing fetus. Second, compared to multiparous women and in fact regardless of BMI, primiparous women may require additional support during pregnancy as well as labor and birth. This is a view shared by others (Dahlen, Barclay, \& Homer, 2008; Miller \& Skinner, 2012). For example, Dahlen, Barclay, and Homer (2010a) found that first-time pregnant women reacted to the unknown of labor quite differently to those women experiencing a subsequent birth. The level of preparation, support, information, communication, choices, and sense of control all explained the diversity in the first-time experiences of birthing women. American authors Fair and Morrison (2012) similarly found that first-time pregnant women's perception of being in control significantly predicted birth satisfaction with high levels of correlating satisfaction levels. The work of both Schempf and Strobino (2009) and Goler, Armstrong, Taillac, and Osejo (2008) takes this one step further, suggesting that women who develop a high internal loci of control during the antenatal period are also more likely to be receptive to positive health modifications and strategies which ultimately contribute to better birth outcomes and increased birth satisfaction.

Thus, maternal obesity together with primiparity represents a complex issue which requires a holistic approach to care. With this in mind, a contemporary approach to antenatal care provision for extremely obese pregnant women experiencing their first pregnancy may be the answer. This is not a new idea with specifically developed programs, such as centering in pregnancy focusing on other specific groups of women showing improved perinatal outcomes (Grady \& Bloom, 2004; Ickovics et al., 2007). Whereas medically focused antenatal care aims to identify and manage potential complications, midwifery care focuses on providing woman-centered care using a holistic approach. A reconceptualization of antenatal care provision, drawing on the skill set of both professional groups, to better meet the needs of obese women may improve outcomes and be more acceptable to women, possibly resulting in positive experiences and improved birth outcomes. 
Although the numbers included in this clinical observational study are small, the findings do support the need for further research, which should include the development and testing of appropriate interventions (such as models of care) to identify the most effective way to meet the needs of this client group.

\section{LIMITATIONS}

Potential limitations and biases included inconsistency in data presentation. Although the Queensland Perinatal Data form requests prepregnancy weight and height to calculate BMI, clinical audit consistently identified booking weight as being recorded rather than prepregnancy weight resulting in the more serious systematic error. This is, however, a consistent finding reported by others (CMACE, 2010). In addition, retrospective cohort data is primarily based on perinatal databases. A recent review of Australian maternity data collections identified significant gaps in available data, with models of maternity care and continuity of care often poorly reported (Australian Institute of Health and Welfare, 2011). A further limitation may be sample bias. Although data were collected over a 2-year period in an effort to increase numbers, the sample size remained small and the power may not have been sufficient to identify statistical differences within the groups. In addition, only collecting data from one study site limits the generalization of the findings.

\section{CONCLUSION}

This study has identified that current service provision to extremely obese women experiencing their first birth at the study site may be contributing to suboptimal outcomes. The high stillbirth rate is an alarming finding and warrants urgent further research in this area. To improve outcomes, and reduce the CS rate, maternity providers need to use a primary health care approach to identify possible strategies which will be acceptable to obese women. The development of targeted maternity care aimed at meeting the needs of obese women experiencing their first birth may well be the answer to improving both outcomes and satisfaction for obese women. To inform service development, research needs to focus on identifying what service provision would most likely be used by this group of women. Qualitative studies are therefore required to answer this question for local populations.

\section{NOTE}

1. Excludes two extremely premature stillborn babies born at 22 and 27 weeks' gestation.

\section{REFERENCES}

Abenhaim, H. A., Kinch, R. A., Morin, L., Benjamin, A., \& Usher, R. (2007). Effect of prepregnancy body mass index categories on obstetrical and neonatal outcomes. Archives of Gynecology and Obstetrics, 275(1), 39-43. http://dx.doi.org/10.1007/s00404-006-0219-y

Alfirevic, Z., Devane, D., \& Gyte, G. (2006). Continuous cardiotocography (CTG) as a form of electronic fetal monitoring (EFM) for fetal assessment during labour. Cochrane Database of Systematic Reviews, (3), CD006066. http://dx.doi.org/10.1002/14651858.CD006066

Athukorala, C., Rumbold, A. R., Willson, K. J., \& Crowther, C. A. (2010). The risk of adverse pregnancy outcomes in women who are overweight or obese. BMC Pregnancy \& Childbirth, 10, 56. Retrieved from http://www .biomedcentral.com/1471-2393/10/56

Australasian Maternity Outcomes Surveillance System. (2010). Current studies: Women with morbid obesity. Retrieved from http://www.amoss.com.au/page.php?id=38

Australian Institute of Health and Welfare. (2011). Maternity data in Australia: A review of sources and gaps (AIHW Bulletin No. 87. Cat. No. AUS 136). Canberra, Australia: Author.

Belizán, J. M., Althabe, F., \& Cafferata, M. L. (2007). Health consequences of the increasing caesarean section rates. Epidemiology, 18(4), 485-486.

Benninger, C., \& McCallister, J. (2010). Asthma in pregnancy. The Nurse Practitioner, 35(4), 10-19. doi: 10.1097/01. npr.0000369937.32234.05

Bhattacharya, S., Campbell, D. M., Liston, W. A., \& Bhattacharya, S. (2007). Effect of body mass index on pregnancy outcomes in nulliparous women delivering singleton babies. BMC Public Health, 7, 168-175.

Blaine, B. E., Rodman, J., \& Newman, J. M. (2007). Weight loss treatment and psychological well-being: A review and meta-analysis. Journal of Health Psychology, 12(1), 66-82. doi: 10.1177/1359105307071741

Brennan, D. J., Murphy, M., Robson, M. S., \& O'Herlihy, C. (2011). The singleton, cephalic, nulliparous woman after 36 weeks of gestation: Contribution to overall cesarean delivery rates. Obstetrics and Gynecology, 117(2, Part 1), 273-279.

Caughey, A., Sundaram, V., Kaimal, A., Gienger, A., Cheng, Y., McDonald, K., . . Bravata, D. (2009). Systematic review: Elective induction of labor versus expectant management of pregnancy. Annals of Internal Medicine, 151, 252-263. 
Centre For Maternal and Child Enquiries. (2010). Maternal obesity in the UK: Findings from a national project. London: Author.

Centre for Maternal and Child Enquiries. (2011). Saving mothers' lives: Reviewing maternal deaths to make motherhood safer: 2006-2008. The eighth report on confidential enquiries into maternal deaths in the United Kingdom. British Journal of Obstetrics and Gynaecology, 118(Suppl. 1), 1-203.

Chu, S. Y., Kim, S. Y., Lau, J., Schmid, C. H., Dietz, P. M., Callaghan, W. M., \& Curtis, K. M. (2007). Maternal obesity and risk of stillbirth: A metaanalysis. American Journal of Obstetrics and Gynecology, 197(3), 223-228. http:// dx.doi.org/10.1016/j.ajog.2007.03.027

Commonwealth of Australia. (2011). National maternity services plan 2010. Barton, Australia: Author.

Cupul-Uicab, L. A., Skjaerven, R., Haug, K., Melve, K. K., Engel, S. M., \& Longnecker, M. P. (2012). In utero exposure to maternal tobacco smoke and subsequent obesity, hypertension, and gestational diabetes among women in the MoBa cohort. Environmental Health Perspectives, 120(3), 355. doi: 10.1289/ehp.1103789

Dahlen, H. G., Barclay, L. M., \& Homer, C. (2008). Preparing for the first birth: Mothers' experiences at home and in hospital in Australia. Journal of Perinatal Education, 17(4), 21-32. http://dx.doi.org/10.1624/105812408x364143

Dahlen, H. G., Barclay, L. M., \& Homer, C. S. E. (2010a). 'Reacting to the unknown': Experiencing the first birth at home or in hospital in Australia. Midwifery, 26(4), 415-423. http://dx.doi.org/10.1016/j.midw.2008.07.009

Dahlen, H. G., Barclay, L. M., \& Homer, C. S. E. (2010b). The novice birthing: Theorising first-time mothers' experiences of birth at home and in hospital in Australia. Midwifery, 26(1), 53-63. http://dx.doi: .org/10.1016/j. midw.2008.01.012

Decision Support Services Queensland Health. (2012). Births, mothers and outpatient research. Births and deliveries between 01/01/2009 to 31/12/2010.

Dodd, J. M., Grivell, R. M., Nguyen, A. M., Chan, A., \& Robinson, J. S. (2011). Maternal and perinatal outcomes by body mass index. Australian \& New Zealand Journal of Obstetrics \& Gynaecology, 51, 136-140.

Fair, C. D., \& Morrison, T. E. (2012). The relationship between prenatal control, expectations, experienced control, and birth satisfaction among primiparous women. Midwifery, 28(1), 39. http://dx.doi.org/10.1016/j. midw.2010.10.013

Goler, N. C., Armstrong, M. A., Taillac, C. J., \& Osejo, V. M. (2008). Substance abuse treatment linked with prenatal visits improves perinatal outcomes: A new standard. Journal of Perinatology, 28(9), 597-603. http://dx.doi. org/10.1038/jp.2008.70
Grady, M. A., \& Bloom, K. C. (2004). Pregnancy outcomes of adolescents enrolled in a CenteringPregnancy program. Journal of Midwifery \& Women's Health, 49(5), 412-420. http://dx.doi.org/10.1016/j.jmwh.2004.05.009

Gülmezoglu, A., Crowther, C., \& Middleton, P. (2006). Induction of labour for improving birth outcomes for women at or beyond term. Cochrane Database of Systematic Reviews, (4), CD004945. http://dx.doi.org/10.1002/ 14651858.CD004945.pub2

Hartz, D. L., Foureur, M., \& Tracy, S. K. (2012). Australian caseload midwifery: The exception or the rule. Women and Birth, 25(1), 39-46. http://dx.doi.org/10.1016/j. wombi.2011.01.001

Hatem, M., Sandall, J., Devane, D., Soltani, H., \& Gates, S. (2008). Midwife-led versus other models of care for childbearing women. Cochrane Database of Systematic Reviews, (4), CD004667. http://dx.doi.org/10.1002/ 14651858.CD004667.pub2

Health Statistics Centre Queensland Health. (2010). Mothers by BMI and method of birth, Gold Coast Hospital and Birth Centre, Queensland 2009. Extracted May 20, 2010.

Health Statistics Centre Queensland Health. (2012). Perinatal statistics Queensland 2010: Queensland health. Brisbane, Queensland: Queensland Health.

Henderson, J., Hornbuckle, J., \& Doherty, D. (2007). Models of maternity care: A review of the evidence. Western Australia Department of Health. Retrieved from http:// www.healthnetworks.health.wa.gov.au/docs/Models_ of_Maternity_Care_Review_of_Evidence.pdf

Hildingsson, I., Karlström, A., \& Nystedt, A. (2011). Women's experiences of induction of labour-Findings from a Swedish regional study. Australian \& New Zealand Journal of Obstetrics \& Gynaecology, 51(2), 151-157. http:// dx.doi.org/10.1111/j.1479-828X.2010.01262.x

Hodnett, E., Gates, S., Hofmeyr, G., Sakala, C., \& Weston, J. (2011). Continuous support for women during childbirth. Cochrane Database of Systematic Reviews, (2), CD003766. http://dx.doi.org/10.1002/14651858.CD003766.pub3

Homer, C., Brodie, P., \& Leap, N. (2008). Midwifery continuity of care: A practical guide. Sydney, Australia: Churchill Livingstone.

Huang, H. Y., Yang, W., \& Omaye, S. T. (2011). Intimate partner violence, depression and overweight/obesity. Aggression and Violent Behavior, 16(2), 108-114. doi: 10.1016/j.avb.2010.12.005

Ickovics, J. R., Kershaw, T. S., Westdahl, C., Magriples, U., Massey, Z., Reynolds, H., \& Rising, S. S. (2007). Group prenatal care and perinatal outcomes: A randomized controlled trial. Obstetrics \& Gynecology, 110(2), 330339. http://dx.doi.org/10.1097/AOG.0b013e31816bf6bd

Jackson, D. J., Lang, J. M., Swartz, W. H., Ganiats, T. G., Fullerton, J., Ecker, J., \& Nguyen, U. (2003). Outcomes, safety, 
and resource utilization in a collaborative care birth center program compared with traditional physician-based perinatal care. American Journal of Public Health, 93(6), 999-1006. http://dx.doi.org/10.2105/ajph.93.6.999

Khashan, A. S., \& Kenny, L. C. (2009). The effects of maternal body mass index on pregnancy outcome. European Journal of Epidemiology, 24(11), 697-705. http://dx.doi .org/10.1007/s10654-009-9375-2

King, V. J., Pilliod, R., \& Little, A. (2010). Rapid review: Elective induction of labor. Portland, OR: Center for Evidence-based Policy.

Knight, M., Kurinczuk, J., Spark, P., \& Brocklehurst, P. (2010). Extreme obesity in pregnancy in the United Kingdom. Obstetrics \& Gynecology, 115(5), 989-997.

Li, Z., McNally, L., Hilder, L., \& Sullivan, E. (2011). Australia's mothers and babies 2009 (Perinatal Statistics Series No. 25. Cat. No. PER 52). Sydney, Australia: Australian Institute of Health and Welfare, National Perinatal Epidemiology and Statistics Unit.

Mantakas, A., \& Farrell, T. (2010). The influence of increasing BMI in nulliparous women on pregnancy outcome. European Journal of Obstetrics, Gynecology, and Reproductive Biology, 153, 43-46.

Maternity Care Working Party, Royal College of Midwives, Royal College of Obstetricians and Gynaecologists, National Childbirth Trust. (2007). Making normal birth a reality: Consensus statement from the Maternity Care Working Party. London, United Kingdom: Maternity Care Working Party.

Mbah, A. K., Kornosky, J. L., Kristensen, S., August, E. M., Alio, A. P., Marty, P. J., .. . Salihu, H. M. (2010). Super-obesity and risk for early and late pre-eclampsia. British Journal of Obstetrics and Gynaecology, 117(8), 997-1004. http:// dx.doi.org/10.1111/j.1471-0528.2010.02593.x

Miller, S., \& Skinner, J. (2012). Are first-time mothers who plan home birth more likely to receive evidence-based care? A comparative study of home and hospital care provided by the same midwives. Birth, 39(2), 135-144. http://dx.doi.org/10.1111/j.1523-536X.2012.00534.x

Mozurkewich, E., Chilimigras, J., Koepke, E., Keeton, K., \& King, V. (2009). Indications for induction of labour: A best-evidence review. British Journal of Obstetrics and Gynaecology, 116(5), 626-636.

NSW Department of Health. (2010). Maternity-Towards normal birth in NSW. A woman friendly birth initiative: Protecting, promoting and supporting normal birth. Sydney, Australia: Author.

Page, L. (2008). Being a midwife to midwifery: Transforming midwifery services. In K. Fahy, M. Foureur, \& C. Hastie (Eds.), Birth territory and midwifery guardianship: Theory for practice, education and research (pp. 115-129). Edinburgh, Scotland: Butterworth Heinemann.
Pickering, R. P., Grant, B. F., Chou, S. P., \& Compton, W. M. (2007). Are overweight, obesity, and extreme obesity associated with psychopathology? Results from the national epidemiologic survey on alcohol and related conditions. The Journal of Clinical Psychiatry, 68(7), 998-1009.

Poobalan, A., Aucott, L., Gurung, T., Smith, W., \& Bhattacharya, S. (2009). Obesity as an independent risk factor for elective and emergency caesarean delivery in nulliparous women-Systematic review and meta-analysis of cohort studies. Obesity Reviews, 10, 28-35.

Sandall, J., Soltani, H., Gates, S., Shennan, A., \& Devane, D. (2013). Midwife-led continuity models versus other models of care for childbearing women. Cochrane Database of Systematic Reviews, (8), CD004667. http:// dx.doi.org/10.1002/14651858.CD004667.pub3

Schempf, A. H., \& Strobino, D. M. (2009). Drug use and limited prenatal care: An examination of responsible barriers. American Journal of Obstetrics and Gynecology, 200(4), 412.e411-412.e10. http://dx.doi.org/10.1016/j. ajog.2008.10.055

Sebire, N. J., Jolly, M., Harris, J. P., Wadsworth, J., Joffe, M., Beard, R. W., . . Robinson, S. (2001). Maternal obesity and pregnancy outcome: A study of 287,213 pregnancies in London. International Journal of Obesity and Related Metabolic Disorders: Journal of the International Association for the Study of Obesity, 25(8), 1175-1182. http://dx.doi.org/10.1038/sj.ijo.0801670

Slavin, V., \& Fenwick, J. (2012). Use of a Classification tool to determine groups of women that contribute to the cesarean section rate: Establishing a baseline for clinical decision making and quality improvement. International Journal of Childbirth, 2(2), 85.

Slavin, V., Fenwick, J., \& Gamble, J. (2013). Pregnancy care and birth outcomes for women with moderate to superextreme obesity. Women and Birth, 26(3), 179-184.

Stivanello, E., Knight, M., Dallolio, L., Frammartino, B., Rizzo, N., \& Fantini, M. P. (2010). Peripartum hysterectomy and cesarean delivery: A population-based study. Acta Obstetricia et Gynecologica Scandinavica, 89(3), 321-327.

Turnbull, D., Baghurst, P., Collins, C., Cornwell, C., Nixon, A., Donnelan-Fernandez, R., \& Antoniou, G. (2009). An evaluation of Midwifery Group Practice. Part I: Clinical effectiveness. Women and Birth, 22(1), 3-9. http:// dx.doi.org/10.1016/j.wombi.2008.10.001

Ursavas, A., Karadag, M., Nalci, N., Ercan, I., \& Gozu, R. O. (2008). Self-reported snoring, maternal obesity and neck circumference as risk factors for pregnancy-induced hypertension and preeclampsia. Respiration, 76(1), 33.

Usha Kiran, T. S., Hemmadi, S., Bethel, J., \& Evans, J. (2005). Outcome of pregnancy in a woman with an increased body mass index. British Journal of Obstetrics 
and Gynaecology, 112(6), 768-772. http://dx.doi.org/ 10.1111/j.1471-0528.2004.00546.x

World Health Organization. (2000). Obesity: Preventing and managing the global epidemic (WHO Tech. Rep. Series 894). Geneva, Switzerland: Author.

World Health Organization. (2012). Controlling the global obesity epidemic. Retrieved from: http://www.who.int/ nutrition/topics/obesity/en/

Correspondence regarding this article should be directed to Valerie J. Slavin, RM, M Adv Prac (HC Research), BSc Mid, Dip HE Mid, 45 Harmsworth Road, Pacific Pines, Queensland, 4211, Australia. E-mail: val.slavin@bigpond.com
Valerie J. Slavin, RM, M Adv Prac (HC Research), BSc Mid, Dip HE Mid, School of Nursing and Midwifery and Maternity and Family Unit, Centre for Health Practice Innovation (HPI), Griffith Health Institute, Griffith University, and Queensland Health Gold Coast Hospital.

Jennifer Fenwick, RM, PhD, School of Nursing and Midwifery and Maternity and Family Unit, Centre for Health Practice Innovation (HPI), Griffith Health Institute, Griffith University, and Queensland Health Gold Coast Hospital.

Jenny Gamble, RM, PhD, School of Nursing and Midwifery and Maternity and Family Unit, Centre for Health Practice Innovation (HPI), Griffith Health Institute, Griffith University. 